\title{
Sexual Experience and Contraceptive Use among Unmarried Adolescent University Students in Mandalay, Myanmar
}

\section{Myitzu T01*, Thida1 ${ }^{1}$, Khaing NT$^{2}$, Kyaw TS1, Yadanar $\mathrm{A}^{1}$ and Theingi $\mathbf{M}^{2}$}

${ }^{1}$ Department of Medical Research, Pyin Oo Lwin Branch, Myanmar

${ }^{2}$ Maternal and Reproductive Health Division, Department of Public Health, Myanmar

\section{Research Article}

Volume 3 Issue 1

Received Date: November 29, 2018

Published Date: January 28, 2019

DOI: $10.23880 /$ phoa- 16000132

*Corresponding author: Myitzu Tin Oung, Department of Medical Research, Pyin Oo Lwin Branch, Myanmar, Email: myitzu@gmail.com

\section{Abstract}

Increase in proportion of sexually active adolescents and insufficient use of effective contraceptive methods contributed to an increase in unintended teenage pregnancy, abortion and STI among adolescents in Myanmar. The study investigated the sexual behavior and contraceptive use among unmarried adolescent university students. A crosssectional descriptive study was conducted using an anonymized, self-administered questionnaire with adolescents who were attending at universities situated in Mandalay District. The six universities were randomly selected, from which 960 students were recruited using a probability proportional to size (PPS) sampling method. After excluding cases with missing background information, 850 students were included in the analysis. Descriptive statistics were used to describe the findings. Among 850 students, 12.4\% were from health-related universities and the remaining was from other universities. A total of 135 unmarried students (16\%) responded that they had sexual experience. The mean age of their first sexual exposure was 17.9 years (17.6 years for girls and 18.1 years for boys). Their contraceptive use was high (more than 75\%) and was higher when they had sex with persons who were not their regular partners (more than 90\%). Among them, approximately 50\% used contraception consistently and the commonly used method was the male condom. The mostly cited reasons for not using contraception consistently were unaware of contraceptive methods, unplanned sex, forced sex, unwillingness to use contraception by the partner and fear of contraceptive side effects. The higher percentage of students with better contraceptive and STI knowledge and those with more permissive attitudes towards men's and women's premarital sex used contraception more consistently. About $11 \%$ of students or their partners who had had sexual exposure in the past (12 out of 110) had an experience of pregnancy, and 10 out of 12 pregnancies were unwanted and nine ended with miscarriage. The findings indicated the need for improving knowledge of contraception and sexually transmitted infections among adolescent students to promote consistent contraceptive use and effective prevention of unwanted pregnancy, abortion and sexually transmitted infections.

Keywords: Sexual behavior; Contraceptive use; Adolescents; University students 
Abbreviations: AIDS: Acquired Immunodeficiency Syndrome; ARH: Adolescent Reproductive Health; ASFR: Age Specific Fertility Rate; CSW: Commercial Sex Workers; FRHS: Fertility and Reproductive Health Survey;

HIV: Human Immunodeficiency Virus; PPS: Probability proportional to size; STI: Sexually Transmitted Infections.

\section{Introduction}

Sexual activity among adolescents is increasing globally. Studies have shown that sexual maturation and sexual activity initiation are occurring at a much younger age in the current generation than the previous one $[1,2]$. Together with early sexual relationships, teenagers have inadequate reproductive health knowledge, limited knowledge of and access to contraceptive methods, resulting in low contraceptive use [3], leading to higher rates of adolescent pregnancy and abortion.

Adolescent pregnancy is a significant public health problem worldwide. Almost 1 million teenage girls become pregnant every year. Seventy-eight percent of adolescent pregnancies are unplanned, accounting for approximately one-fourth of all unintended pregnancies annually [4]. Regardless of whether the pregnancy is planned or unplanned, or whether childbirth takes place within or outside marriage, early pregnancy can have harmful effects on a girl's physical, long-term emotional, economic, and social well-being. Adolescent pregnancies and childbirths carry greater risks of morbidity and mortality for both mothers and babies. The risk of dying from pregnancy-related causes for adolescent mothers is two times higher than adult mothers [5]. Especially, unintended early pregnancy and childbearing has huge socio-economic implications on families, society, adolescent mothers themselves, and their babies [6].

In Myanmar, the adolescent fertility rate (age specific fertility rate [ASFR] of women aged 15-19) has increased twofold within less than a decade, from 17 per 1000 live births in 2007 [7] to 36 per 1000 live births in 2015 [8]. Increase in proportion of sexually active adolescents and insufficient use of effective contraceptive methods contributed to an increase in unintended teenage pregnancy and abortion. The proportion of women who undergo induced abortion was highest in the youngest age group 15 to 19 years, amounting to $11.4 \%$ of total pregnancies of that age group [9]. The 2004 Family and Youth Survey noted that $32 \%$ of male youth and $45 \%$ of female youth (15-24 years) reported that they had experienced sexually transmitted infections, such as pain on urination, itching, swelling in groin area, and abdominal pain [10].
The present study was conducted among adolescent university students. Change in norms about premarital sexual relationships among educated adolescents together with peer pressure, being away from their family, and lack of access to formal channels of reproductive health information and services, university adolescents can be particularly susceptible to high risk sexual behavior. In addition, most sexually active adolescents do not want to have children because they are studying, are young or not married, and therefore are prone to the risk of unintended pregnancy and induced abortion unless they are using an effective contraceptive method. According to the 2007 Fertility and Reproductive Health Survey (FRHS), women with university education had the second highest rate of abortion (9\%) after married adolescents (11.39\%) [9].

This study investigated sexual behavior and pattern of contraceptive use with different types of sexual partners among adolescent university students and the reasons for using or not using contraception among contraceptive non-users. The findings could provide baseline data for policy makers and education planners to develop appropriate evidence-based strategies, intervention programs and curricula for adolescent students to prevent unintended pregnancy, unsafe abortion and sexually transmitted infections.

\section{Materials and Methods}

A cross-sectional descriptive study was conducted using an anonymized, self-administered questionnaire to obtain information from the adolescent university students aged 16-19 years. The study was conducted from September 2015 to August 2016. The study was carried out in universities situated in Mandalay district which is one of the largest districts and the main commercial, educational, and health centre of Upper Myanmar. There were 12 universities in Mandalay district including 7 health-related universities and 5 non-health related universities which cover a wide range of disciplines such as medicines, education, economics, law, literature, science, computer and engineering.

Three health-related and three non-health-related universities were randomly selected. Then, a probability proportional to size (PPS) sampling was attempted to obtain the required samples 960 from the six selected universities. After obtaining the number of students from each selected university, individual students were recruited using stratified simple random sampling (stratified by academic year and sex). 
The sample size was calculated using $\mathrm{R}$ statistical software version 2.11.1. Assuming the proportion of students who have sexual experience to be $50 \%$ as the safest choice as it was not know the proportion of adolescents who had sexual experience in this target population; confidence interval as $95 \%$; delta as 0.05 ; anticipated missing values as $20 \%$; design effect as 2 due to the multistage nature of the sampling method, the minimum required sample size was 922. The study recruited 960 students from selected universities. The analysis was first performed with 850 students after excluding cases with missing values in background characteristics. This study focused on only 135 unmarried adolescent university students who had sexual experience.

The self-administered questionnaire included questions about background characteristics of participating students, knowledge of contraception, knowledge of Sexually Transmitted Infections (STI), attitude towards premarital sex, sexual behavior and contraceptive practice with different sexual partners.

The questionnaire assessing knowledge of contraception included their understanding of contraception, awareness of contraceptive methods and knowledge of condom and emergency contraceptive pills. There were ten questions and one correct answer gave one score and the score summed up and divided into three categories; no/low knowledge, moderate knowledge and high knowledge.

The questionnaire assessing knowledge of STIs included sexually transmitted infections they have ever heard, symptoms of STIs, factors predisposing to acquisition of STIs, and ways to prevent STIs. There were six questions and one correct answer gave one score and the score summed up and divided into three categories; no/low knowledge, moderate knowledge and high knowledge.

There were eight questions to assess attitudes towards premarital sex. It was categorized as (1) Liberal attitude (Agree on statement: "women/men should be able to have sex with any man/women they want before marriage) (2) More permissive attitude (Agree on statement: "women/men may have sex with their acquaintances before marriage?") (3) Permissive attitude (Agree on statement: "women/men may have sex with steady boyfriend/girlfriend before marriage") (4) Less permissive attitude (Agree on statement: "women/men should never have sex before marriage?") (5) No idea. Data entry was done using EpiData 3.02 software.
Descriptive data analysis was performed by using SPSS version 20.

\section{- Ethical considerations}

The study was approved by the Ethics Review Committee of the Department of Medical Research, Myanmar and WHO Research Ethics Review Committee. Only verbal informed consent was obtained from the participants before they were enrolled in the study to maintain anonymity and confidentiality.

\section{Results}

The mean age of respondents was 18.3 years and the ratio of male to female was 0.72 . Among 850 students, $12.4 \%$ were from health-related universities and the remaining three-fourth of students (87.6\%) was recruited from other universities, i.e. non-health-related universities. Around a quarter of students were recruited from each academic term, except the fifth year from which $4.5 \%$ of respondents were included in the study (Table 1 ).

\begin{tabular}{|c|c|c|}
\hline Variables & Number & Percentage \\
\hline Age & $18.31 \pm 1.24$ (Range 16-20) \\
\hline \multicolumn{3}{|c|}{ Sex } \\
\hline Male & 357 & 42 \\
\hline Female & 493 & 58 \\
\hline \multicolumn{3}{|c|}{ Type of University } \\
\hline Health-related & 105 & 12.4 \\
\hline Others & 745 & 87.6 \\
\hline \multicolumn{3}{|c|}{ Academic year } \\
\hline First & 247 & 29.1 \\
\hline Second & 171 & 20.1 \\
\hline Third & 200 & 23.5 \\
\hline Fourth & 194 & 22.8 \\
\hline Fifth & 38 & 4.5 \\
\hline
\end{tabular}

Table 1: Participants' characteristics

\section{Marital status and sexual experiences}

Among the respondents, 93.9\% were unmarried and $38.7 \%$ had a boy/girlfriend at that moment. It was found 143 out of 850 respondents had ever had sexual exposure in their life, 135 unmarried and 8 married students. Among 842 unmarried adolescent students, 16\% (135) had sexual exposure, in which $63.7 \%$ were boys and $36.3 \%$ were girls (Table 2). 


\begin{tabular}{|c|c|c|}
\hline Variable & Number & Percent \\
\hline \multicolumn{3}{|c|}{ Current marital status( $(n=850)$} \\
\hline Unmarried & 798 & 93.9 \\
\hline Married & 8 & 0.9 \\
\hline No response & 44 & 5.2 \\
\hline \multicolumn{3}{|c|}{ Currently, do you have a boy/girlfriend? $(n=850)$} \\
\hline Yes & 329 & 38.7 \\
\hline No & 442 & 52 \\
\hline Not applicable (Married) & 8 & 0.9 \\
\hline No response & 71 & 8.4 \\
\hline \multicolumn{3}{|c|}{ Have you ever had sex with someone? $(n=850)$} \\
\hline Yes & 135 & 15.9 \\
\hline No & 652 & 76.7 \\
\hline Not applicable (Married) & 8 & 0.9 \\
\hline No response & 55 & 6.5 \\
\hline
\end{tabular}

Table 2: Marital status and sexual experiences among the respondents.

The following data analysis was based on the 135 unmarried adolescent university students who had sexual experience in their life.

\section{First Sexual Experience and Contraceptive Use}

The mean age of first sexual exposure among respondents was 17.9 years. The mean age of first sexual exposure among girls was 0.5 years younger than boys (17.6 years for girls and 18.1 years for boys). The youngest age at first sexual exposure was 7 years for girls and 15 years for boys. The mean age of the person with whom they had sex (19.2 years) was generally 1.3 years older than the respondents. Among the students who could not provide the exact information about age of that person, more than half of their first sexual partners were older than the respondents; one-tenth of students had sex with younger persons for the first time, and about onefifth were likely to be the same age with the respondents.

First sexual exposure was mostly with their boyfriends or girlfriends (75.4\%), and $4.8 \%$ was with their fiancé. About $10 \%$ was with those who were not in relationship (7.9\% with acquaintance, $0.8 \%$ with relatives and $1.6 \%$ with strangers). Few students (9.5\%) had sexual exposure with commercial sex workers (CSW) when they had sex for the first time. The first sexual exposure of two-third of the students was planned and they were willingly accepted to that experience (Table 3).

\begin{tabular}{|c|c|}
\hline Variable & Descriptive statistics \\
\hline \multicolumn{2}{|c|}{ Age at first sexual exposure (All) $(n=125)$} \\
\hline Mean & 17.9 years \\
\hline Median & 18.0 years \\
\hline SD & 1.7 vears \\
\hline Range & $7-20$ years \\
\hline \multicolumn{2}{|c|}{ Age at first sexual exposure (Boys) $(n=78)$} \\
\hline Mean & 18.1 years \\
\hline Median & 18.0 years \\
\hline SD & 1.1 years \\
\hline Range & $15-20$ years \\
\hline \multicolumn{2}{|c|}{ Age at first sexual exposure (Girls) $(n=47)$} \\
\hline Mean & 17.6 years \\
\hline Median & 18.0 years \\
\hline SD & 2.3 years \\
\hline Range & $7-20$ vears \\
\hline \multicolumn{2}{|c|}{ Age of the person whom the respondent had sex with $(n=91)$} \\
\hline Mean & 19.2 year \\
\hline Median & 19.0 year \\
\hline SD & 2.0 year \\
\hline Range & $16-29$ year \\
\hline
\end{tabular}

Table 3A: First sexual experience of the respondents.

Note: " $n$ " is the number of students who responded the question. 


\begin{tabular}{|c|c|c|}
\hline Variable & Frequency & Percentage \\
\hline \multicolumn{3}{|c|}{ Estimated age of the person with whom the respondent had sex (n = 40) } \\
\hline \multicolumn{3}{|c|}{ For those who did not know the exact age } \\
\hline Older than the respondent & 27 & 67.5 \\
\hline Younger than the respondent & 4 & 10 \\
\hline Same age as the respondent & 9 & 22.5 \\
\hline Relationship with the person with whom the respondent had sex (n = 126) \\
\hline Fiancé (legally engaged) & 6 & 4.8 \\
\hline boy/girl friend & 95 & 75.4 \\
\hline Acquaintance & 10 & 7.9 \\
\hline Relatives & 1 & 0.8 \\
\hline Ctrangers (Not known each other) & 2 & 1.6 \\
\hline CSW & 12 & 9.5 \\
\hline \multicolumn{2}{|c|}{ Planned or not (n=124) } \\
\hline Planned & 92 & 74.2 \\
\hline Not planned & 32 & 25.8 \\
\hline Acceptability to the first sex (n = 126) \\
\hline Willingly accepted & 93 & 73.8 \\
\hline Accepted, not willingly & 28 & 22.2 \\
\hline Forced or coerced & 5 & 4.0 \\
\hline
\end{tabular}

Table 3B: First sexual experience of the respondents (continued). Note: " $n$ " is the number of students who responded the question.

Out of students who had sexual experience, $76.2 \%$ used some type of contraception at their first sexual exposure. The mostly cited contraceptive methods were male condom (58.3\%), emergency pills $(17.7 \%)$ and combined oral contraceptive pills $(15.6 \%)$. Their main reason for using contraception was to prevent pregnancy. About half of respondents also wanted to prevent STI and HIV. Half of students gave the reason for not using contraception as "Unplanned sex". The commonly given reason from the remaining half were "Don't know about contraceptive method" (26.1\%), "Fear of side effects" $(17.4 \%)$ and "Don't know how to get a method" (13.0\%).

\section{Sexual Experience and Contraceptive Use with Different Types of Sexual Partner}

Among 135 unmarried adolescent students, 77.8\% had ever had a regular partner (referring to someone with whom you had an ongoing relationship - like a spouse, lover, or boyfriend or girlfriend) in their life and $67.8 \%$ had such kind of partners in the past 12 months. Most of them had one regular partner and $10 \%$ had more than one. The contraceptive use was fairly high (nearly $80 \%$ ) among students who had a regular partner in the past 12 months.

Approximately one third of participants (29.6\%) had ever had a casual partner (referring to someone with whom you had sex casually and you did not expect to continue sexual relation in the future - a casual acquaintance or someone you just met) in their life and about a quarter $(23.8 \%)$ had sex with causal partner in the past 12 months. The contraceptive practice of students with causal partners was pretty high (91.2\%).

The percentage of having sex commercial sex workers (referring to partners with whom you gave money in exchange for sex) was $17.8 \%$ and it was $14.1 \%$ for the past 12 month period. Contraceptive use with commercial sex workers was also high (90.0\%) (Figure 1). 


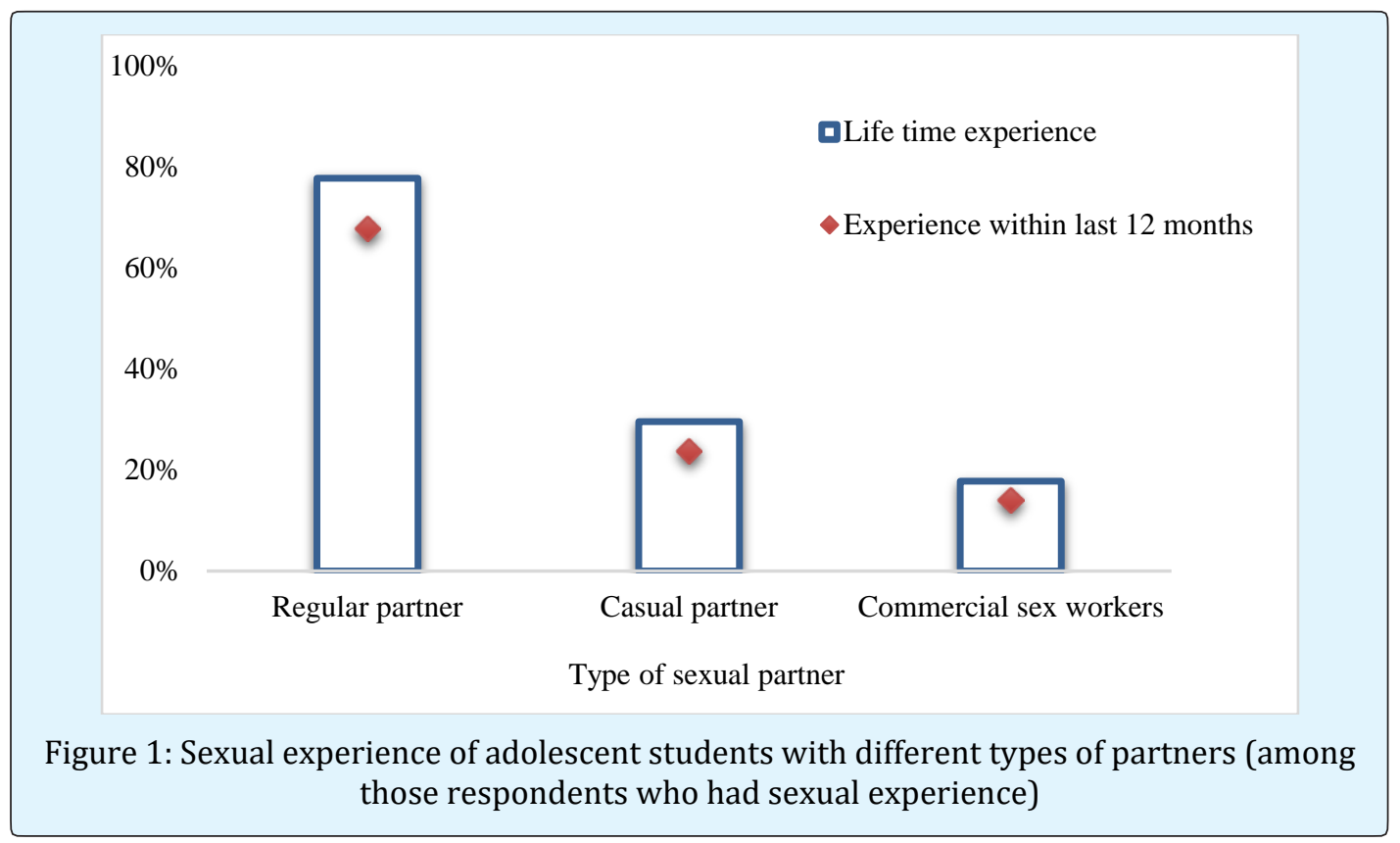

There were some participants who did not respond questions related to sexual experience and contraceptive use with different types of sexual partners $(5-8 \%$ for

questions related to regular partners, around $25 \%$ for questions related to casual partners and nearly $40 \%$ for questions related to commercial sex workers) (Figure 2).

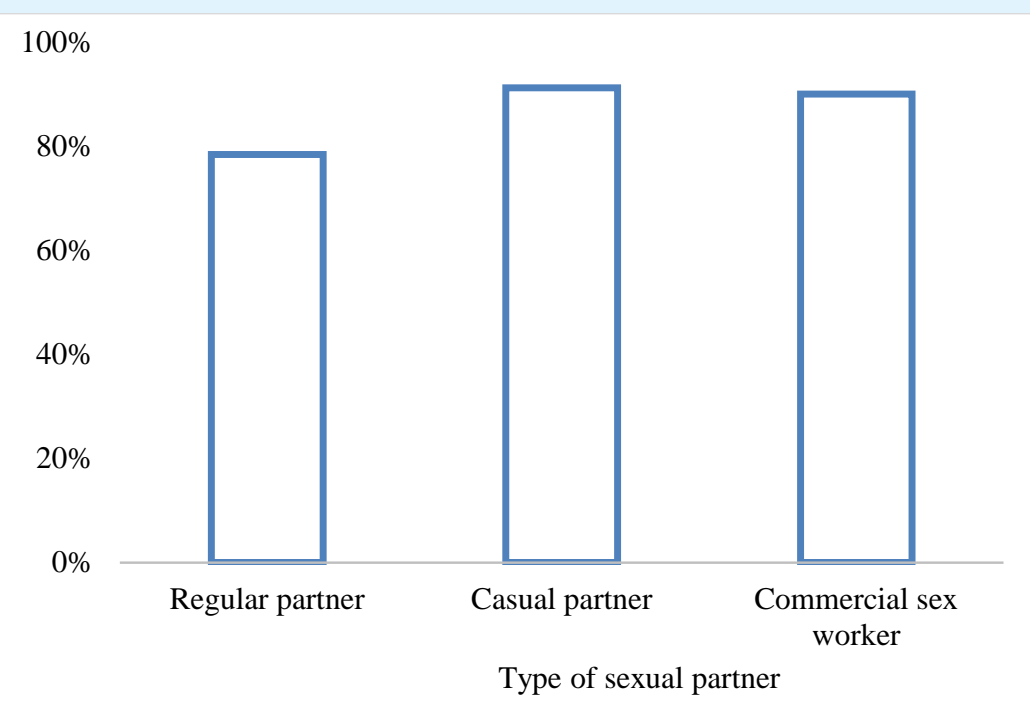

Figure 2: Consistency of contraceptive use with different types of sexual partner. (among those respondents who had sexual experience in the past 12 months)

In gerneal, it can be said the contraceptive use among participating students was high, especially with nonregular partners. However, the consistent contraceptive use (the percentage of student who responded that he/she always used any contraceptive method whenever he/she had sex) was comparatively low, accounted for around $50 \%$, and this percentage was not very different by type of sexual partners (Figure 3). 


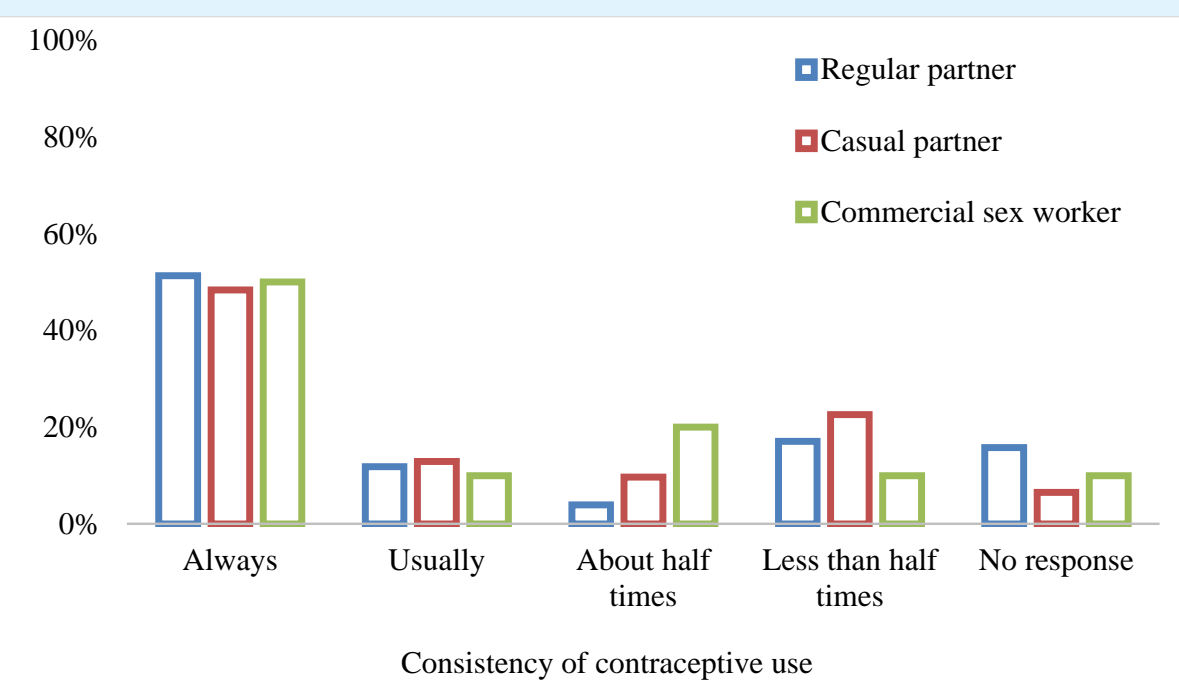

Figure 3: Consistency of contraceptive use with different types of sexual partner (among those who had sexual experience in the past 12 months)

Among those who used contraception when they had sex with different types of partners in the last 12 months, male condom was the most commonly used contraceptive method $(67.1 \%$ with regular partners, $83.9 \%$ with casual partners and $83.3 \%$ with commercial sex workers). Other commonly used contraceptive methods were emergency contraceptive pills and combined oral contraceptive pills. Some other methods they used were withdrawal method, safe period, injection and female condom (Figure 4).

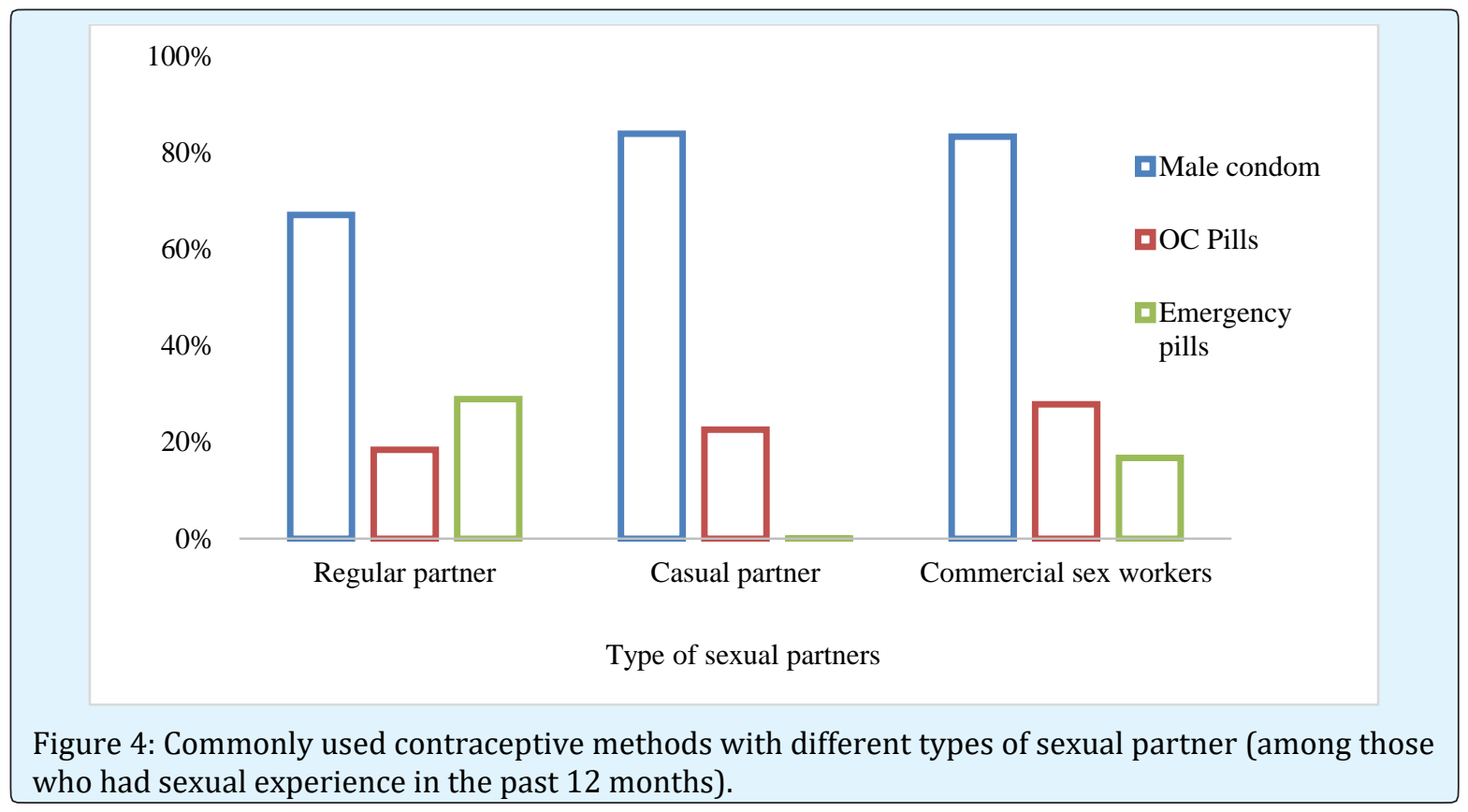

\section{Reasons for using and not using contraception with different types of sexual partners}

The most common reason for consistent contraceptive use with different types of sexual partner was to avoid getting pregnancy $(80-90 \%)$ and the others were to prevent sexually transmitted infections $(45-55 \%)$ and to prevent HIV/AIDS (25-50\%). 
Among those who did not use contraception or did not use contraception consistently with regular partners, the most commonly stated reasons for were "Don't know about contraceptive method" (52.9\%), "Fear of side effects" (29.4\%) and "Experience of forced sex" (20.6\%). Some other reasons were "Don't know how to get methods", "Intention to have a baby", "Partners prefer not to use" (14.7\% for each). Among them, $17.6 \%$ responded that they forgot to use and only $2.9 \%$ said they did not use because it was unplanned sex. The most common reasons for not using or inconsistent use of contraception with casual partners were "Don't know about contraceptive method" (36.8\%), "Fear of side effect" (26.3\%) and unplanned sex (26.3\%), and with CSW were "Don't know about contraceptive method" (70\%), "Don't know how to get a method" (12.5\%) and "Fear of side effect" (12.5\%).

\section{Respondents' characteristics and contraceptive use with regular partners}

The findings showed that the percentages of boys and girls who used contraception consistently with regular partners were similar (52.3\% and 55.2\%). The findings indicated that more percentage of students from nonhealth-related universities used contraception consistently than those from health-related universities (33.3\% and $56.2 \%$ respectively). The percentage of consistent contraceptive use was higher among the students with higher level of contraceptive knowledge and STI knowledge. The students with more permissive attitudes towards premarital sex used contraceptive method more consistently than those with less permissive and permissive attitudes (Table 4).

\begin{tabular}{|c|c|c|c|c|}
\hline \multicolumn{5}{|c|}{ Consistency of contraceptive use } \\
\hline Variables & Non use & Inconsistent use & Consistent use & Total \\
\hline Male & 5 & 16 & 23 & 44 \\
\hline & $11.4 \%$ & $36.4 \%$ & $52.3 \%$ & $100.0 \%$ \\
\hline Female & 4 & 9 & 16 & 29 \\
\hline & $13.8 \%$ & $31.0 \%$ & $55.2 \%$ & $100.0 \%$ \\
\hline \multicolumn{5}{|c|}{ Types of university } \\
\hline Health-related universities & 2 & 4 & 3 & 9 \\
\hline & $22.2 \%$ & $44.4 \%$ & $33.3 \%$ & $100.0 \%$ \\
\hline Other universities & 7 & 21 & 36 & 64 \\
\hline & $10.9 \%$ & $32.8 \%$ & $56.2 \%$ & $100.0 \%$ \\
\hline \multicolumn{7}{|c|}{ Contraceptive knowledge } \\
\hline Low level knowledge & 2 & 1 & 1 & 4 \\
\hline & $50.0 \%$ & $25.0 \%$ & $25.0 \%$ & $100.0 \%$ \\
\hline Medium level knowledge & 6 & 19 & 27 & 52 \\
\hline & $11.5 \%$ & $36.5 \%$ & $51.9 \%$ & $100.0 \%$ \\
\hline High level knowledge & 1 & 5 & 11 & 17 \\
\hline & $5.9 \%$ & $29.4 \%$ & $64.7 \%$ & $100.0 \%$ \\
\hline
\end{tabular}

Table 4A: Consistency of contraceptive use with regular partner.

\begin{tabular}{|c|c|c|c|c|}
\hline & \multicolumn{3}{|c|}{ Consistency of contraceptive use } & \\
\hline Variables & Non use & Inconsistent use & Consistent use & Total \\
\hline STI knowledge & & & & \\
\hline Low level knowledge & 2 & 6 & 2 & 10 \\
\hline
\end{tabular}




\begin{tabular}{|c|c|c|c|c|}
\hline & $20.0 \%$ & $60.0 \%$ & $20.0 \%$ & $100.0 \%$ \\
\hline Medium level knowledge & 4 & 13 & 20 & 37 \\
\hline & $10.8 \%$ & $35.1 \%$ & $54.1 \%$ & $100.0 \%$ \\
\hline High level knowledge & 3 & 5 & 14 & 22 \\
\hline & $13.6 \%$ & $22.7 \%$ & $63.6 \%$ & $100.0 \%$ \\
\hline \multicolumn{7}{|c|}{ Attitude towards men's premarital sex } \\
\hline Less permissive attitude & 5 & 11 & 11 & 27 \\
\hline & $18.5 \%$ & $40.7 \%$ & $40.7 \%$ & $100.0 \%$ \\
\hline Permissive attitude & 3 & 7 & 12 & 22 \\
\hline & $13.6 \%$ & $31.8 \%$ & $54.5 \%$ & $100.0 \%$ \\
\hline More permissive attitude & 0 & 6 & 15 & 21 \\
\hline & $0.0 \%$ & $28.6 \%$ & $71.4 \%$ & $100.0 \%$ \\
\hline Attitudes towards women's premarital sex & 32 \\
\hline Less permissive attitude & 6 & 10 & 16 & $100.0 \%$ \\
\hline & $18.8 \%$ & $31.2 \%$ & $50.0 \%$ & 19 \\
\hline Permissive attitude & 2 & 5 & 12 & $100.0 \%$ \\
\hline & $10.5 \%$ & $26.3 \%$ & $63.2 \%$ & 10 \\
\hline More permissive attitude & 0 & 9 & $52.6 \%$ & $100.0 \%$ \\
\hline & $0.0 \%$ & $47.4 \%$ & & \\
\hline
\end{tabular}

Table 4B: Consistency of contraceptive use with regular partner (continued)

\section{Pregnancies and Miscarriage Experiences}

Out of 110 respondents who had sexual experience (excluding those 25 students who did not respond the question), $10.9 \%$ (12 students) had an experience of being pregnant themselves or their partners. A high number of such pregnancies (10 out of 12 pregnancies) were unwanted. As a consequence, nine out of 12 pregnancies ended with abortion.

\section{Discussion}

Adolescents often engage in risky sexual behavior, resulting in unintended social and health outcomes. A wider knowledge of adolescent reproductive health is necessary to achieve a focused and coordinated response to the priority issues which affect the well-being of adolescents in Myanmar. This study investigated the adolescent reproductive health (ARH) related issues including sexual behavior and contraceptive practices among adolescent university students in Mandalay district, aiming at improving ARH programs in Myanmar.

The study found that $16 \%$ of unmarried adolescent university students had sexual exposure and mean and median age of the first sexual exposure among the respondents was 18 years. Most of the persons with whom they had sex were older than the participants. The percentage of sexual exposure among adolescents in this study was relatively higher than other studies in Myanmar $[5,6,10]$ because this study used the selfadministered questionnaire for collecting data rather than face-to-face interview. Many researchers believe that more complete and truthful information on sensitive topics can be obtained with self-administered questionnaires because self-administering assured the respondents' anonymity and privacy. The respondents can feel free to provide honest responses. However, this percentage was not high compared with other countries where there is more liberal attitude towards sexual activity such as Thailand [11], Nigeria [12], Chile [13] and China [14].

The findings showed that the first sexual experience of adolescent students was mostly with their partners, planned, willingly accepted and safe (i.e. use contraception) but there were still some students who had experienced unwanted and unsafe sex. Their responses of reasons for not using contraception, such as 
unawareness of the methods and how to access a method and lack of adequate information about contraceptive use, should be taken into account in designing ARH program to promote safer sex practice among adolescents since their first sexual experience.

Approximately $80 \%$ students had sex with their regular partners and around 20\% had sexual experience with casual partners or commercial sex workers. However, $30-40 \%$ of students did not respond to that particular question. Due to high non-response rate, the actual figures regarding type of sexual partners with whom adolescent university students had sex could not be determined. More innovative approach, like anonymous online survey, should be used for future research to get a $100 \%$ response rate in conducting research related to sexual behaviour of the unmarried young.

A high percentage of students in this study used some contraceptive method (more than 80\%) with different types of sexual partners, which was quite higher than the finding from the Family and Youth Survey in which 26\% of young males aged 15-19 who have ever had sexual intercourse used something to prevent pregnancy and 30\% used to prevent STI/HIV [5]. Obviously, the main reason for high contraceptive use in the current study was the study participants were urban educated adolescents who had better access to contraceptive methods.

However, many adolescents (around 50\%) engage in sex with different types of sexual partner without using contraception consistently. The finding is more or less similar with other studies, in which $60 \%$ of youth use condom consistently with commercial sex workers (CSW) [15]; $61.5 \%$ of male medical students and $36.6 \%$ of community male youths who had sexual experience consistently used condoms [16]. The most cited reasons for non-use or inconsistent contraceptive use were: lack of knowledge about contraceptive method, being afraid of contraceptive side effects and unawareness of how to access method. This means that even educated adolescents still need information about contraception and about how to access methods.

The higher percentage of students with better contraceptive and STI knowledge and with more permissive attitudes towards men's and women's premarital sex used contraception more consistently with different type of sexual partners. Comparing students from health-related universities, students from nonhealth related universities used contraception more consistently. The findings indicated that rather than being students from health-related universities, better reproductive health knowledge and more permissive attitudes among students is more important for consistent contraceptive use.

Unmarried girls in Myanmar are vulnerable to unwanted pregnancies because currently the RH services are targeted to married women [17]. Lack of knowledge and access to contraceptive services may be the contributing factors for high percentage of unwanted pregnancy and pregnancy-related deaths among adolescents. The study found a high percentage of unwanted pregnancy and a high percentage of abortion among those who became pregnant, indicating the urgent need of effective interventions to prevent unwanted adolescent pregnancy and abortion.

\section{Conclusion}

The findings call for an action for implementing strategies which can promote a consistent and effective use of contraception among adolescent university students to prevent unwanted pregnancy and abortion. This can be achieved by ensuring access to adolescentfriendly sexual and reproductive health services through strengthening the capacity of health institutions, by promoting safer sex practice through comprehensive sex education using mass media campaigns, by empowering girls to protect themselves from getting unwanted pregnancies and by implementing strategic programs that engage boys in girls' sexual and reproductive health and rights.

\section{Funding}

Funding for conducting this research was provided by the World Health Organization (Special Programme of Research, Development and Research Training in Human Reproduction).

\section{Acknowledgements}

We thank the Department of Medical Research, Ministry of Health and Sports, Myanmar for allowing to conduct this research and the World Health Organization (Special Programme of Research, Development and Research Training in Human Reproduction) for providing financial support to conduct this research. We also thank to all responsible persons from study universities who cooperated well and who provided any assistance in conducting this study and all university students participated in this study. 


\section{References}

1. Ajayi AA, Marangu LT, Miller J, Paxman JM (1991) Adolescent sexuality and fertility in Kenya: A survey of knowledge, perceptions, and practices. Stud in Fam Plann 22(4): 205-216.

2. Morris L (1994) Sexual behavior of young adults in Latin America. Advances in Population 2: 231-252.

3. Oni TE, Prinsloo EAM, Nortje JD, Joubert G (2005) High school student's attitudes, practices and knowledge of contraception in Jozini, KwaZulu-Natal. SA Fam Pract 47(6).

4. Goyal M, Zhao H, Mollen C (2009) Exploring emergency contraceptive knowledge, prescription practices, and barriers to prescription for adolescents in the emergency department. Paediatrics 123(3): 765-770.

5. Rosen JE (2004) Adolescent health and development (AHD): A resource guide for World Bank operations staff and government counterparts. Health, Nutrition, and Population Family (HNP) of the World Bank's Human Development Network. HNP discussion paper. Washington, DC: World Bank.

6. Hassani KF (2010) Changes in sexual behavior and hormonal contraceptives use among Finnish adolescents. Academic dissertation, Faculty of Medicine of the University of Tampere 7(201): 7-12

7. Department of Population (2009) Myanmar Fertility and Reproductive Health Survey 2007. Department of Population, Ministry of Immigration and Population, Yangon, Myanmar and UNFPA.

8. Ministry of Health and Sports (2017) Myanmar Demographic and Health Survey 2015-16, Ministry of Health and Sports, Nay Pyi Taw, Myanmar and The DHS Program, ICF, Rockville, Maryland, USA.
9. Ministry of Immigration and Population (2009) Myanmar Fertility and Reproductive Health Survey 2007. Yangon: Department of Population and UNFPA.

10. Ministry of Immigration and Population and UNFPA (2006) Family and Youth Survey 2004: Country Report. Yangon.

11. The Henry J, Kaiser Family Foundation (2002) Survey snapshot. Substance use and risky sexual behavior: Attitudes and practices among adolescents and young adults. The Kaiser Family Foundation's National Survey of Youth Knowledge and Attitudes on Sexual Health Issues.

12. Narzary PK (2009) Knowledge and use of contraception among currently married adolescent women in India. Stud Home Comm Sci 3(1): 43-49.

13. Ma Q, Ono-Kihara $\mathrm{M}$, Cong $\mathrm{L}, \mathrm{Xu} \mathrm{G}$, Zamani $\mathrm{S}$, et al. (2006) Sexual behavior and awareness of Chinese university students in transition with implied risk of sexually transmitted diseases and HIV infection: A cross-sectional study. BMC Public Helath. 18(6): 232.

14. Repossi A, Araneda JM, Bustos L, Puente C, Rojas C (1994) Sexual behavior and contraceptive practices among university students. Send to Rev Med Chil 122(1): 27-35.

15. Min Thwe, Aye Myat Soe, Tin Aung (2005) Behavioural Surveillance Survey 2003: General Population and Youth. Ministry of Health.

16. San San Htay, Myo Oo, Yoshitoku Yoshida, Harun-OrRashid, and Junichi Sakamoto (2010) Risk behaviors and associated factors among medical students and community youths in Myanmar. Nagoya J Med Sci 72(1-2): 71-81.

17. Ministry of Health and World Health Organization. Myanmar national strategic plan on adolescent health and development 2009-2013. 